Bull. Austral. Math. Soc.

VOL. $70(2004)$ [351-351]

\title{
WITT KERNELS OF BI-QUADRATIC EXTENSIONS IN CHARACTERISTIC 2: ADDENDUM
}

\author{
HAMZA AHMAD
}

In a recent referee's report reviewing [2], it was pointed out to me that Theorem 2.2 in [1] was already known in the literature, and is (originally) due to Mammone and Moresi in [3]. Also in [3], the authors establish the excellence of inseparable quadratic extensions in a shorter way than I presented in [1]. As the paper [3] was unknown to me at the time of submitting [1], I hope by this note to acknowledge and credit [3] for the result(s).

\section{REFERENCES}

[1] H. Ahmad, 'Witt kernels of bi-quadratic extensions in characteristic 2', Bull. Austral. Math. Soc. 69 (2004), 433-440.

[2] H. Ahmad, 'Witt kernels of purely inseparable quartic extensions', Linear Algebra Appl. (to appear).

[3] P. Mammone and R. Moresi, 'Formes quadratiques, algèbres à division et extensions multiquadratiques inséparables', Bull. Belg. Math. Soc. Simon Stevin 2 (1995), 311-319.

Department of Mathematical Sciences

Saginaw Valley State University

University Center, MI 48710

United States of America

e-mail: hyahmad@svsu.edu

Received 26th July, 2004

Copyright Clearance Centre, Inc. Serial-fee code: 0004-9727/04 \$A2.00+0.00. 